\title{
The Relationship between Renewable Energy and Economic Growth in a Time of Covid-19: A Machine Learning Experiment on the Brazilian Economy
}

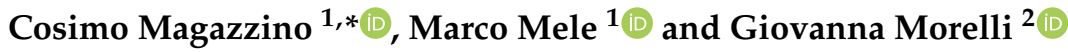 \\ 1 Department of Political Sciences, Roma Tre University, 00145 Rome, Italy; marco.mele@uniroma3.it \\ 2 Faculty of Political Sciences, University of Teramo, 64100 Teramo, Italy; gmorelli@unite.it \\ * Correspondence: cosimo.magazzino@uniroma3.it
}

Citation: Magazzino, C.; Mele, M.; Morelli, G. The Relationship between Renewable Energy and Economic Growth in a Time of Covid-19: A Machine Learning Experiment on the Brazilian Economy. Sustainability 2021, 13, 1285. https://doi.org/ $10.3390 /$ su13031285

Academic Editor: José Luis Domínguez-García Received: 28 December 2020

Accepted: 20 January 2021

Published: 26 January 2021

Publisher's Note: MDPI stays neutral with regard to jurisdictional claims in published maps and institutional affiliations.

Copyright: (C) 2021 by the authors Licensee MDPI, Basel, Switzerland. This article is an open access article distributed under the terms and conditions of the Creative Commons Attribution (CC BY) license (https:/ / creativecommons.org/licenses/by/ $4.0 /)$.

\begin{abstract}
This paper examines the relationship between renewable energy consumption and economic growth in Brazil, in the Covid-19 pandemic. Using an Artificial Neural Networks (ANNs) experiment in Machine Learning, we tried to verify if a more intensive use of renewable energy could generate a positive GDP acceleration in Brazil. This acceleration could offset the harmful effects of the Covid-19 global pandemic. Empirical findings show that an ever-greater use of renewable energies may sustain the economic growth process. In fact, through a model of ANNs, we highlighted how an increasing consumption of renewable energies triggers an acceleration of the GDP compared to other energy variables considered in the model.
\end{abstract}

Keywords: renewable energy; economic growth; Covid-19; Artificial Neural Networks; Brazil

\section{Introduction}

The world has been facing an unprecedented humanitarian, social, and economic crisis since February 2020 due to the Covid-19 pandemic. The Organisation for Economic Cooperation and Development (OECD) is warning the entire international economic system about the negative impact that the Coronavirus will have on the world. The estimates, made so far, outweigh the worst economic forecasts. Therefore, the OECD recommends urgent economic and fiscal policy measures. As early as March 2020, the OECD had released a report that estimated that the Covid-19 crisis was able to halve the growth of the world economy by 2020. Subsequently, the adverse effects of the pandemic could go on until 2022. Now, as the weeks go by, the scenario is getting worse. Therefore, the economic emergency of Covid-19 requires targeted economic policy intervention by all countries. This pandemic is the third major economic, financial, and social "shock" of the 21st century, following the attacks of 11 September 2001, and the global economic-financial crisis of 2008. Among the adverse effects of the crisis, the collapse of production in all countries affected by the pandemic could occur. This situation would generate damage to global value chains, with adverse outcomes on consumption and consumer confidence. Furthermore, although severe measures being implemented are essential to contain the virus, the situation is pushing economies into an unprecedented deep freezing state, from which the recovery will not be direct or automatic. Thus, in addition to taking action to minimize the loss of human lives, a coordinated effort against this new great economic crisis is also a priority, which will continue even when the worst of the health crisis has passed.

On a theoretical level, we can say that this pandemic will affect world economies through three different channels: (1) mortality-affects production, as it permanently removes some people from the workforce; (2) illness, hospitalization, and absenteeismproduction is temporarily penalized; (3) efforts to avoid contagion-people change their behavior in the event of an epidemic, with quarantine preventing travel to/from infected regions and reducing the consumption of services, e.g., restaurants, tourism, entertainment, public transport, and offline purchases. 
The economic fallout and adverse effects of this pandemic will also affect the Brazilian economy. The country will, therefore, have to implement a strategic plan to deal with this new shock. If Brazil was able to anticipate the adverse effects of contagion on the economy, through targeted economic policies, it could slow down the process of economic crisis. In our opinion, the policy choices that Brazil should implement must be based on a rapid process of structural change in the economy. In particular, in this paper, we recommend increasing investment in renewable energy, since this choice could accelerate GDP growth. This acceleration, therefore, could mitigate the effects of an economic recession. In fact, Brazil has great potential for all renewable sources, thanks to its geographical position, which provides an excellent cycle of nature concerning climate issues. The country has abundant resources of solar, wind, biomass, and ocean energy. This makes it possible to maintain the long-term renewable feature-which differentiates the Brazilian energy matrix from the world matrix. The considerable natural resources of the country allow the realization of totally sustainable projects, of rapid construction and with competitive generation costs, capable of supporting the growing electricity demand in the country and of bringing economic development to the communities. Relevant transmission networks will have to accompany this development and efficiently connect new production centers to the Brazilian megalopolises and all consumption centers.

Furthermore, thanks to the development of interconnections within Brazil and neighboring countries, it will be possible to generate a system capable of responding to the challenges deriving from renewable energies. This condition will assist in the creation of a single Latin American electricity market. Intelligent distribution networks will be indispensable for the management of the energy flows of this new energy system through digital platforms marked by growing penetration of electricity in end uses, distributed generation, renewable sources, electric mobility, and the need for ever-higher quality of service.

Promoting the energy industry is, therefore, one of the biggest challenges for the largest country in South America. The Northeast region is the primary producer of wind energy. With 135 parks, Rio Grande do Norte is the state where most of the energies produced to use the force of the winds. There are $3678.85 \mathrm{MW}$ of installed capacity. With 93 parks and $2410.04 \mathrm{MW}$ of installed capacity, the State of Bahia ranks, followed by the State of Ceará, which has 74 parks and 1935.76 MW of installed capacity.

This paper aims to verify, in a Covid-19 time, the possibility that more intensive use of renewable energy (and, therefore, more significant investments in this field) could generate an acceleration of Brazil's GDP. The empirical strategy uses a Machine Learning (ML) approach.

Beside the Introduction, the paper proceeds as follows. Section 2 gives an overview of renewable energy in Brazil. Section 3 describes the renewable energy, pollution emissions, and economic growth relations. Section 3 presents the literature review on this topic. Section 4 shows the data and empirical methodology, while Section 5 comments on the empirical findings. Finally, Section 6 concludes and gives some policy implications.

\section{Renewable Energy, Pollution Emissions, and Economic Growth in Brazil}

Brazil is the eighth largest electricity producer in the world, ranking among the top 10 producers, such as China and the US, and ahead of countries such as France and South Korea. Total energy consumption in Brazil, which includes residential, commercial, and industrial use, was 465 TWh in 2017, 0.8\% more than in 2016.

Brazil has an advantage in energy production: Its resources are among the cleanest in the world. Favored by a vast territory, rich in water and diversified, $81.7 \%$ of the country's energy production capacity comes from renewable sources, compared to a global average of only $23 \%$. Hydroelectric energy alone produces $68.1 \%$ of Brazil's electricity. Some alternative renewable sources still have a relatively small but growing share in the country energy matrix, such as biomass and wind. These sources are encouraged by various government policies, including infrastructure programs, and the National Energy Plan. 
This state energy research company provides support to the Brazilian Ministry of Mines and Energy (BMME).

As regards wind energy, Brazil is the most promising market for wind energy in the Latin American region. In recent years, wind energy has become an increasingly essential component of the national electricity grid. During the energy shortage of 2015, $10 \%$ of the energy came from wind farms, contributing to sustaining the costs of turning on thermal plants. Its efficient local production chain produced most of the equipment and machinery used by wind farms in the country. Moreover, 2017 was a positive year for the global wind industry, with annual installations over $52 \mathrm{GW}$. Brazil returned to the Latin American markets, installing more than $2 \mathrm{GW}$, compared to $116 \mathrm{MW}$ in Chile, and 295 MW in Uruguay (the only Latin American countries with more than $1 \mathrm{GW}$ of installed capacity). At the end of 2017, only nine countries had more than $10 \mathrm{GW}$ of cumulative installed capacity, and Brazil was among them. In 2018, the installed capacity reached $14 \mathrm{GW}$, which corresponds to $8 \%$ of the Brazilian electrical matrix. The sector employs over 190,000 people, supplies electricity to around 22 million homes per month, and reduces $\mathrm{CO}_{2}$ emissions by approximately 21 million tons per year. With nearly $8000 \mathrm{~km}$ of coastline, Brazil has enormous potential for wind power generation, particularly on the Northeastern coast, where there is wind all year round, and many wind farms have already been built.

Conversely solar energy, is a very young industry in Brazil. It starts only after the source has been included in the electricity auctions (the first took place in 2013). The volume contracted since then is almost $4 \mathrm{GW}$. The installed capacity in photovoltaic systems was only 90 MW in early 2017 but has already reached 1 GW. This result placed Brazil in the top 30 globally. According to the report on solar energy, Brazil ranks ninth among the solar additions in the period 2016 to 2020. The best scenario points to $9.5 \mathrm{GW}$ of additional volume. Brazil's share of photovoltaic power plants is expected to grow significantly in the future as incentives drive investment and technology prices to drop. Today, solar parks generate only $0.01 \%$ of national energy. By 2026, the government plans to increase solar energy production to $9660 \mathrm{MW}$, resulting in $4.5 \%$ of the total matrix (considering only the utility-scale). The federal program "Luz para Todos" was created to guarantee universal access to electricity, having benefited more than 16 million people in a decade. The program provided the installation of photovoltaic panels in isolated communities and is a big buyer of this technology.

On the contrary, concerning biofuels, Brazil is an ideal market for this energy resource, and it is still a world leader in the sector. Brazil is the second-largest producer of this type of clean fuel in the world. According to the Brazilian National Oil, Natural Gas and Biofuels Agency (ANP), which is responsible for regulating fuel, $18 \%$ of all fuel consumed today in Brazil comes from renewable sources, mainly ethanol and biodiesel. As the demand for control of green gas emissions is getting stronger all over the world, Brazil has also consolidated its potential as a great exporter.

Sugar cane (for ethanol) and vegetable oil (for biodiesel) are the primary sources of Brazilian biofuels. Ethanol production grew 27.5\% from 2012 levels, reaching 28.5 million cubic meters in 2017. Biodiesel, an incipient in Brazilian refineries at the beginning of the 21st century, has increased production three times in 10 years, ending 2017 with 4.3 million cubic meters produced. Some specific characteristics of the internal market have allowed this expansion of biofuels. Brazil is a world leader in flexible fuel vehicles, with approximately $90 \%$ of the cars produced in the country capable of running on both petrol, ethanol, or any mixed proportion (directly to the pump). Public policies also play an essential role, providing incentives and special programs beyond production, as well as establishing minimum market consumption. The minimum required dilution of ethanol in gasoline was increased to $27 \%$ in 2015 by ANP. The blend of biodiesel in the standard diesel became a requirement in 2008 , with a share of $2 \%$, with a policy of gradual increases over time. At the beginning of 2017, the minimum biodiesel mix required throughout Brazil was $8 \%$, with a gradual increase of $1 \%$ until 2019 , as determined by ANP, with possible further 
improvements shortly. Biofuel production in Brazil is concentrated in the Southeast and Northeast regions, with most sugar cane and mill companies located in São Paulo.

Energy consumption is a growth thermometer. The macro-factors that underlie economic and, therefore, energy growth primarily concern demography. Just thirty years ago, 4.8 billion people lived on the planet, while, according to World Bank, in 2017, the world had seven and a half billion human beings. A 55\% growth naturally strongly affects production, consumption, and energy demand. Moreover, the trend, although it has faded over the last decade, continues to be positive, showing global demographic growth rates of $1.2 \%$ per year. In addition to the quantitative phenomenon, there is a qualitative one.

Another element strongly connected to economic growth concerns the expansion of the middle class. There are vast regions of the world (as in Brazil) where the middle class (the backbone of every growing economic system) expands rapidly, bringing with it a load of desires, possibilities, and needs that, to be satisfied, cannot ignore an increase in energy consumption. In Asia alone, for example, the middle class could go from one and a half billion people today to 3.5 billions in the next 15 years. This explains why, at a historical level (from 1985 to present), the countries that recorded a middle class expansion, as a result of demographic explosion, are the same showing the most significant increases in terms of energy demand. In Brazil, energy consumption increased by $55 \%$; in India, by $100 \%$ while, in a country like France, only by $2 \%$. The combination of these effects led -in the three decades considered above- the world GDP to grow by $600 \%$, against a demographic increase of $55 \%$. Therefore, the growth in energy consumption replicates that of wealth, being its determinant and effect at the same time. This thesis is confirmed even if we leave the purely quantitative parameter of GDP, and adopt correction indices, such as the United Nations Human Development Index (HDI). It is therefore not surprising that the location on the same population growth chart, energy consumption, and HDI trend over the past 25 years returns a consistent growth trend. Of course, there is a well-known downside. Like any human activity, if not regulated, the goal of pursuing growth causes several undesirable effects.

We can think of phenomena such as the growing concentration of wealth in the hands of a small minority of individuals, the risks of social dumping, and the effects on the climate change and the environment. The energy sector and the environmental sector, in particular, are intrinsically linked, and it is known that the actions of governments, supranational institutions, sector players, and NGOs are aimed at attempting to reconcile economic growth with related emissions. By emissions, we mainly mean greenhouse gas emissions, and in particular, $\mathrm{CO}_{2}$, whose abundance in the atmosphere generates an altering climate effect, which facilitates the phenomenon of global warming.

During 2014-2016, promising substantial stability of emissions was recorded, even with a slight decrease in 2015, while wealth continued to grow worldwide. The decoupling between emission trends and growth (the so-called decoupling) is undoubtedly a desirable goal to pursue. However, the virtuous trend of emissions in this period has reversed, according to the surveys of the last few years. $\mathrm{CO}_{2}$ emissions have started to rise again by about $1.5 \%$. This situation launched an alarm to the international community that, for years, has (almost) unanimously embraced the cause of the fight against climate change and emissions.

This result is explained by the fact. In 2017, the energy demand grew by $2.1 \%$, against $0.9 \%$ over the last five years, on average. All its components have increased and contributed to the increase in demand, including coal, reversing the recent downward trend (Figure 1).

Global energy efficiency slowed significantly in 2017. Energy intensity, measured as the energy consumed per unit of economic output, decreased by $1.7 \%$ against $2.3 \%$ in the last three years, and, even more worrying, it is far from what would be required to stay in the wake drawn by the Paris agreements of 2015. 


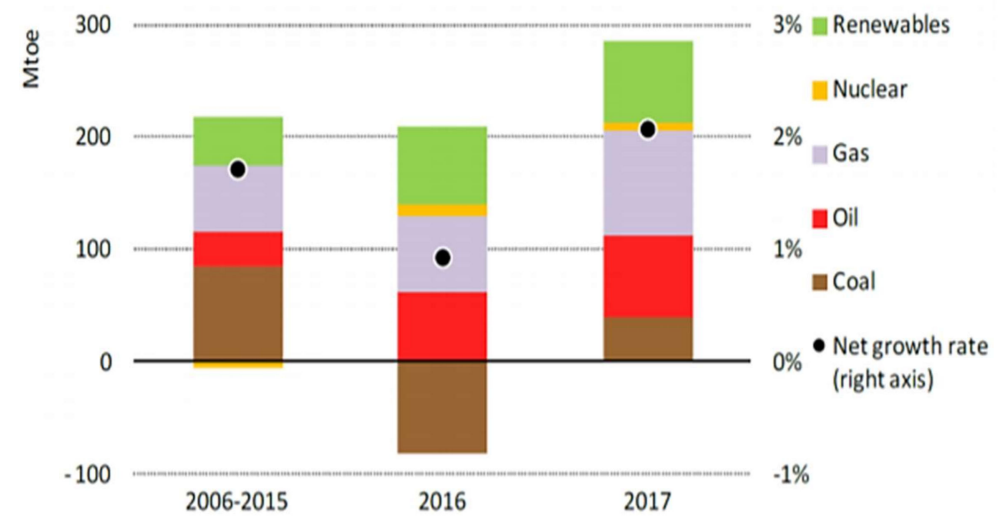

Figure 1. Energy sources. Source: World Bank data.

\section{Literature Review}

The literature on the economic growth-energy consumption nexus has been summarized in [1] and [2], while [3] and [4] report an overview of the electricity demand-GDP relationship. Since the 1970s, several empirical papers have analyzed the link between energy consumption and economic growth. The first study that examined this causality factor was by [5]. However, despite the number of studies on this research topic [6], analyzing 264 scientific analyses (from 1978 to 2014), some of them were not conclusive. In particular, there were paradoxes on the results obtained concerning the fact that the energy consumption can favor economic growth by improving productivity, but also generating damage to the environment (negative externalities). Therefore, in light of these contrasting results, scientific research analyzes the link between energy consumption and economic growth, by structuring it into four alternative hypotheses: growth, conservation, feedback, and neutrality hypothesis. For example, [7] analyzed the relationship among real GDP, $\mathrm{CO}_{2}$ emissions, and energy use in South Caucasus countries and Turkey over the period 1992-2013. Causality results suggest that the conservation hypothesis holds for Armenia, while, for Azerbaijan and Georgia, mixed results emerge, since both feedback hypothesis and growth hypothesis received support by empirical findings. Finally, no evidence of causality exists for Turkey (neutrality hypothesis).

As regards the growth hypothesis, it suggests that energy represents a determinant of economic growth. Therefore, an increase in the use of energy generates a direct effect on it. On the contrary, if the contribution to the use of energy decreases, economic growth is negatively affected [8]. Ref. [9] investigated the nexus between renewable energy consumption and economic growth in Italy. Long-run estimations reveal that, if renewable energy consumption increases by $1 \%$, real GDP decreases by $0.23 \%$. Ref. [10] examined the renewable energy consumption-economic growth nexus in Italy over the period 1970-2007. The Toda and Yamamoto approach shows a unidirectional causal flow, running from renewable energy consumption to aggregate income. Ref. [11] demonstrated this adverse effect as a reduction in energy consumption due, for example, to an energy-saving policy, which generates a very negative impact on the cyclical trend of the economy. Ref. [12] analyzed the US case between 1961 and 2011. Demonstrate the causal link between the use of energy from biomass, the level of employment, and capital by supporting the growth hypothesis. The econometric analysis showed how biomass energy consumption generated a direct and positive causal link to the US economic growth. Ref. [13] confirmed the existence of the growth hypothesis analyzing the case of the OECD countries and the effect of the use of renewable energies on the economic growth of the area. The study concluded that the use of renewable energy, or a mix of it with other energy sources, generated economic growth effects for OECD countries with statistically significant values. Ref. [14] made an econometric estimate of the impact of renewable energy consumption on Germany economic growth It showed that a $1 \%$ increase in renewable energy consumption generates an increase in the economic growth of $0.22 \%$. Ref. [15] used a panel estimation technique to examine 
the energy consumption in a time series from 1990 to 2012 and considered 38 renewable energy-producing countries. Their findings indicate that renewable consumption of energy hugely impacted the long-run economic growth of $57 \%$ of the sample countries. Ref. [16] analyzed the relationship among economic growth, carbon dioxide emissions, and energy use for six Association of South-East Asian Nations (ASEAN) countries over the 1971-2007 years. Using a panel Vector AutoRegression (VAR) technique, the empirical findings show that the response of economic growth to energy use is positive and statistically significant. Thus, the results suggested that for this panel the "growth hypothesis" holds.

According to the conservation hypothesis, a one-way causality effect ranging from economic growth to energy consumption exists. This result suggests the absence of an adverse impact on economic growth when energy consumption decreases. Ref. [17], studying the Israeli case over the period 1980-2013, found evidence of a unidirectional causality running from economic growth to primary energy consumption. Ref. [18] analyzed the case of the Baltic States, through a time-series approach, from 1990 to 2011. Applied results highlighted that the economic growth generated an increase in the consumption of renewable electricity, but not vice versa. Ref. [19] examined the link between renewable energy consumption and economic growth for 17 emerging countries. They concluded that the conservation hypothesis could hold only in the case of Peru, while the growth hypothesis was confirmed in most other countries. Ref. [20] inspected the relationship among economic growth, energy use, and $\mathrm{CO}_{2}$ emissions in Israel over the period 19712006. Causality results suggest that real GDP drives both energy use and $\mathrm{CO}_{2}$ emissions. Ref. [21] used the Granger causality tests in analyzing the US data between 1960 and 2007. The applied findings confirmed a unidirectional causality between the growth of GDP and renewable energy consumption. The conservation hypothesis was also validated in the Turkey case by and [22,23]. Ref. [24] with panel co-integration estimations for 18 emerging economies concluded for a direct correlation between economic growth and consumption of clean energy in which increase in capital would result in a $3.5 \%$ increase in the use of renewable energy, implying that renewable energy consumption will increase tremendously as emerging economies take on.

According to the feedback hypothesis, it affirms that there is a bidirectional relationship between economic growth and energy use. Ref. [25] studied the case of Middle East and North Africa (MENA) countries, discovering a bidirectional causal link between the use of renewable energy and economic growth, but only in the long-run. Ref. [26] analyzed the relationship among economic growth, renewable energies, trade, and economic growth. The results showed the existence of a bidirectional link between renewable energy consumption and economic growth for both, developing and developed countries. In addition, a $1 \%$ increase in renewable energy consumption allows a $0.873 \%$ variation in economic growth in developed countries, and $0.68 \%$ in developing countries. Ref. [27] confirmed the feedback hypothesis, analyzing the relationship between biomass energy consumption and economic growth in the BRIC (Brazil, Russia, India, and China) countries. The results showed a two-way link that ensured a balance between the two long-term variables. Ref. [11] demonstrated how, because of this bidirectional relationship, energy-saving policies could generate a negative effect on the economy, and vice versa. Ref. [28] analyzed the bidirectional causal relationship amongst nuclear energy consumption, $\mathrm{CO}_{2}$ emissions, renewable energy, and economic growth per capita between 1990 and 2013, through panel data methodologies. They discovered the presence of a long-term bidirectional relationship between renewable energy consumption and per capita GDP change. Ref. [29] assessed the relationship between disaggregate energy production and real aggregate income in Italy, using annual data from 1883 to 2009. Causality tests roughly confirm a bidirectional flow in the long-run, so that energy production and economic growth complement each other. Ref. [30] discovered a two-directional connection between economic growth and renewable energy consumption employing Panel Vector Error Correction (PVEC) models for OECD countries over the period 1985-2005. 
The neutrality hypothesis denies the existence of a causal relationship between energy consumption and economic growth. Therefore, an adverse change in energy consumption will not cause a reduction in economic growth. The neutrality hypothesis is confirmed in empirical studies if an increase in economic growth does not cause an increase in energy consumption, and vice versa. Ref. [31] analyzed the relationship among economic growth, carbon dioxide emissions, and energy use for 19 Asia-Pacific Economic Cooperation (APEC) countries 1960-2013. Using a panel VAR technique, a three-variable VAR is estimated. Empirical findings illustrate that no causal relationship emerges between real GDP and energy use, in line with neutrality hypothesis. [32] investigated the relationship among economic growth, carbon dioxide emissions, and energy use for the South Caucasus area and Turkey in the 1992-2013 years. The time-series techniques show results in line with the neutrality hypothesis. Ref. [33] studied the causal relationship between energy consumption and economic growth through a panel VAR on 82 countries over the period 1972-2002. They found that the neutrality hypothesis was valid for low-income countries. Ref. [34] analyzed the relationship between electricity consumption and economic growth for 12 countries of the EU (European Union). They concluded that there was no causal relationship between the variables of their study in the short term. This result confirmed the hypothesis of neutrality. Ref. [35], through a panel co-integration model, analyzed the link between energy consumption and economic growth for 16 Asian countries. The results highlighted the absence of a causal relationship between energy consumption and economic growth in the short-term. In the long run, however, the authors found a one-way causal link that supported the growth hypothesis.

The papers using ML methodologies to estimate the link between energy pollution and economic growth are very recent. Ref. [36] investigated the causal relationship among solar and wind energy production, coal consumption, economic growth, and $\mathrm{CO}_{2}$ emissions for China, India, and the US. The findings, confirmed by three different ML procedures, showed that, while a reduction in overall carbon emissions is predicted in China and the US (resulting from the intensive use of renewable sources of energy), India displays critical predictions of a rise in $\mathrm{CO}_{2}$ emissions. Ref. [37] analyzed 104 countries in a time series from 1993 to 2014. Using the Boosted Regression Trees (BRT) in ML, they stated that renewables is a precondition for sustainable development. Ref. [38], using an Artificial Neural Networks (ANNs) experiment, analyzed the relationship between energy priceenergy supply and economic growth in China, from 1980 to 2010 . They show that the positive effects on economic growth are only visible in the short-term. Ref. [39] studied the interactions of water and energy systems with economic sustainability. They use a variety of ML techniques by comparing results with statistical estimates. They concluded that future studies will need to be supported by empirical evidence in ML.

Ref. [40] analyzed the relationship among economic growth, pollution, and the spread of COVID-19, in India, using a Causal Direction from Dependency (D2C) algorithm. A predictive link among economic growth, energy use, $\mathrm{PM}_{2.5}$, and the spread of Covid19 in India emerges. Ref. [41], through an ANN, demonstrated the threshold value of concentration of $\mathrm{PM}_{2.5}$ and $\mathrm{PM}_{10}$ linked to the spread of the Covid-19 virus in three French cities.

In light of the analysis of how renewable energy sources have contributed to the development of the Brazilian economy, one fundamental point that every research study should focus on is the extension by which the mitigation of carbon emissions is integral in the growth of the country. The economic literature, already in its contributions that are not recent, has analyzed the connections between economic growth and environmental degradation through the so-called Environmental Kuznets Curve (EKC). It states that there is a direct correlation between environmental degradation and economic growth to a certain level, beyond which there is an increase in the quality of environment as income per capita increases [20]. Based on the Intergovernmental Panel on Climate Change report, the renewable energy sources can meet $77 \%$ of the energy needs of the world by 2050 , despite the present figure being relatively as low as 13\% [42]. Most countries wonder 
about the role they can perform in that drastic transformation, given that Brazil has played a significant role in the process, having contributed $44.8 \%$ of clean energy in 2010 . The projected renewable energy production increase to $46.3 \%$ could be small. Still, it does not consider the enormous growth that it will experience in terms of demands of raw energy and the point that, in the next decade, a foundation would be created to facilitate the use of clean energy in the future.

Fossil fuels are the current primary sources of global energy, which makes up to over $80 \%$ of the total power supplied in the world economy [13]. However, the use of fossil fuel across the globe has been met with numerous impediments that have prompted many countries, including Brazil, to find alternative reliable energy sources. Some of the challenges that the Brazilian government faces in the use of fossil fuels is the increasing disconnection between the demand of energy and its supply in the global market, the growing depletion of oil reserves, and emissions of harmful gases in the atmosphere [43]. Carbon, which is a byproduct of the combustion of fossil fuels, is the leading cause of the present human ecological crisis. Concerning the various crises that have rocked the energy sector, lately Brazil has displayed an increasing desire to develop clean and renewable energy sources. Besides the depletion of fossil fuel, the unabated rate of environmental degradation is also another factor that has prompted the Brazilian government to embrace the Green Growth Agenda, which fosters for tandem coexistence of economic growth and environmental conservation [13].

According to [44], renewable energy is highly suitable in reducing the amount of carbon in energy, which is an integral element of mitigating climate. Based on [42], the consumption of renewable energy would minimize the emission of carbon by approximately $8.2 \%$ by 2050 . The use of clean energy technologies also contributes immensely to economic development. It assists in the minimization of dependency on imported fuels. It increases the consumption and accessibility of energy across Brazil to over 1.4 million people who are not fully exposed to renewable energy sources [43]. The spread of renewable energy can also help create job opportunities and facilitate the growth of industries in its underdeveloped areas. Ref. [21] estimated that an increase in energy consumption by $1 \%$ rises Brazilian per capita GDP by $0.12 \%$.

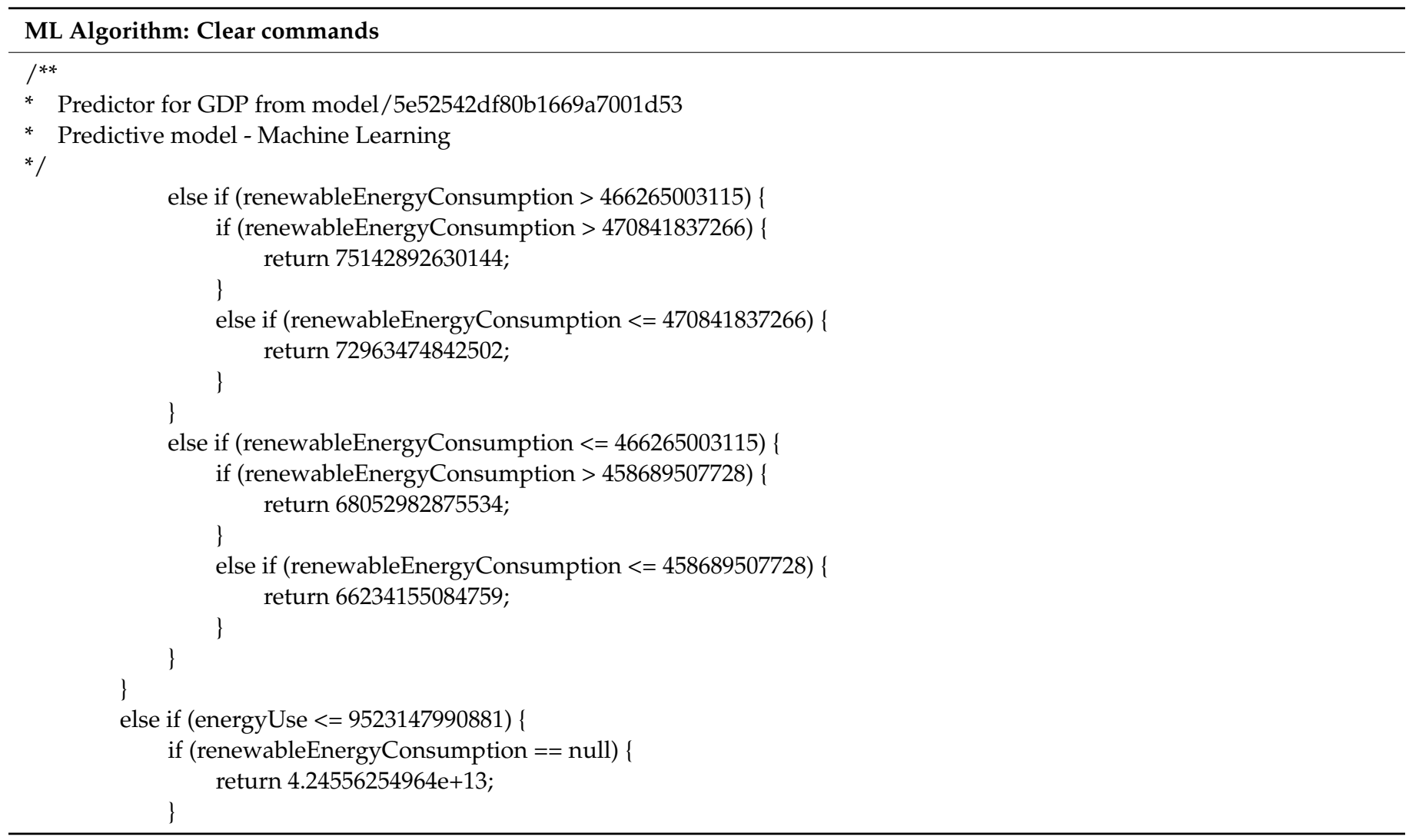




\section{Algorithm: Clear commands}

else if (renewableEnergyConsumption > 457215090163) \{

if (renewableEnergyConsumption $>494014217107$ ) \{

return 34173524419097;

\}

else if (renewableEnergyConsumption $<=494014217107$ ) \{

if (renewableEnergyConsumption > 488196755836) \{

return 36603914991113;

\}

else if (renewableEnergyConsumption $<=488196755836)$ \{

if (renewableEnergyConsumption $>485255955955)$ \{ return 37404332798519;

\}

else if (renewableEnergyConsumption $<=485255955955)$ \{

if (combustibleRenewablesAndWaste > 418851117669) \{ return 36649775984029;

\}

else if (combustibleRenewablesAndWaste $<=418851117669$ ) \{

if (renewableEnergyConsumption > 472421825846) \{ return 36854928917748;

\}

else if (renewableEnergyConsumption $<=472421825846$ ) \{ return 36928457891073;

$$
\}
$$

\}

\}

$$
\}
$$

\}

\}

else if (renewableEnergyConsumption $<=457215090163$ ) \{

if (combustibleRenewablesAndWaste > 383360798070) \{

if (renewableEnergyConsumption > 441666117351) \{

return 62195140163069;

\}

else if (renewableEnergyConsumption $<=441666117351$ ) \{ return 55878862556595; \}

else if (combustibleRenewablesAndWaste $<=383360798070)\{$

if (renewableEnergyConsumption > 432619411834)

if (combustibleRenewablesAndWaste > 349628252668) \{

if (renewableEnergyConsumption > 441289953817) \{ return 37418556362389;

\}

else if (renewableEnergyConsumption $<=441289953817$ ) return 38214610626366;

\}

else if (combustibleRenewablesAndWaste $<=349628252668)\{$ return 41473817272212;

$$
\}
$$$$
\}
$$

else if (renewableEnergyConsumption $<=432619411834$ ) \{

if (renewableEnergyConsumption > 421383264041) \{

return 47043175612282;

\} 
ML Algorithm: Clear commands

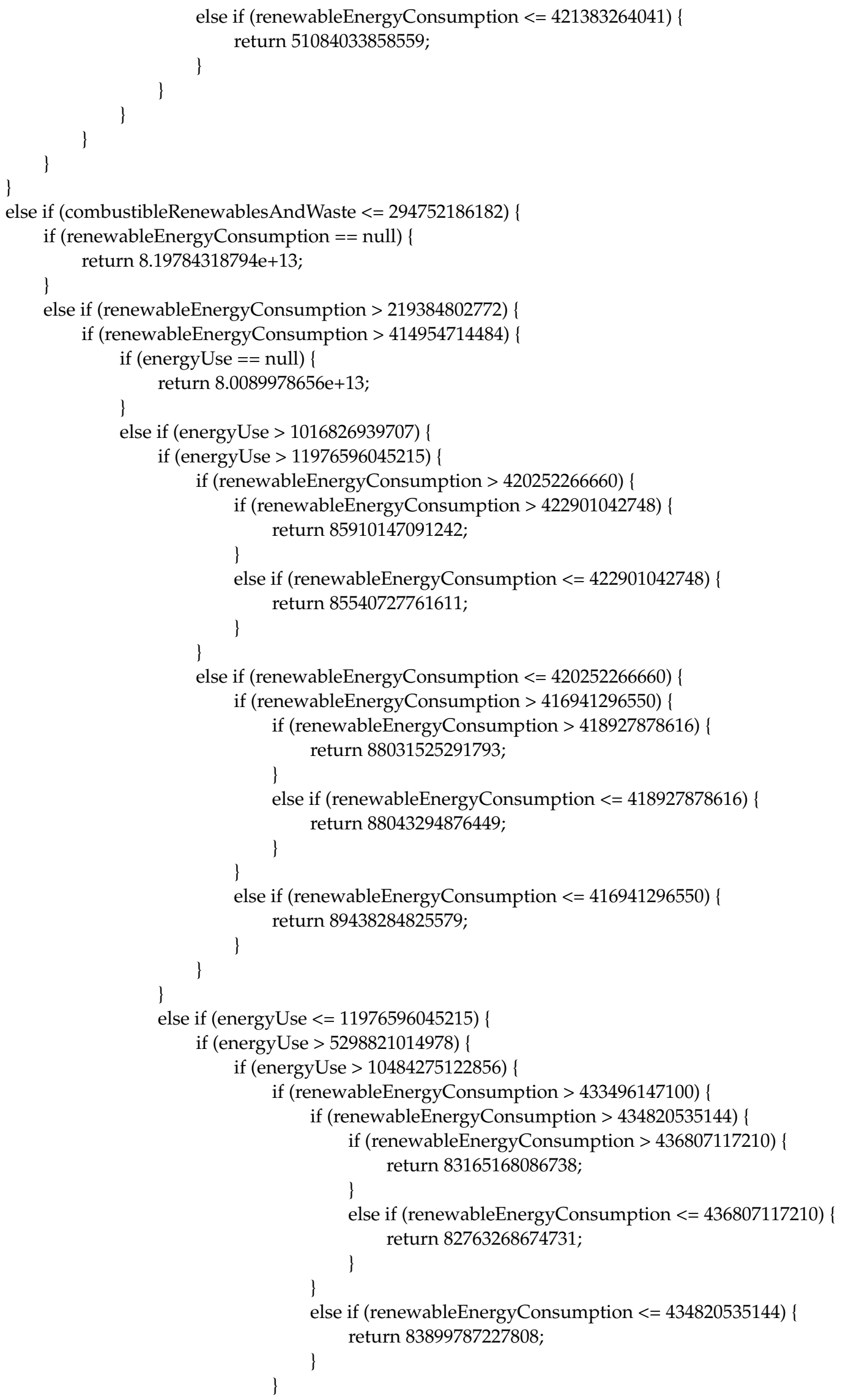




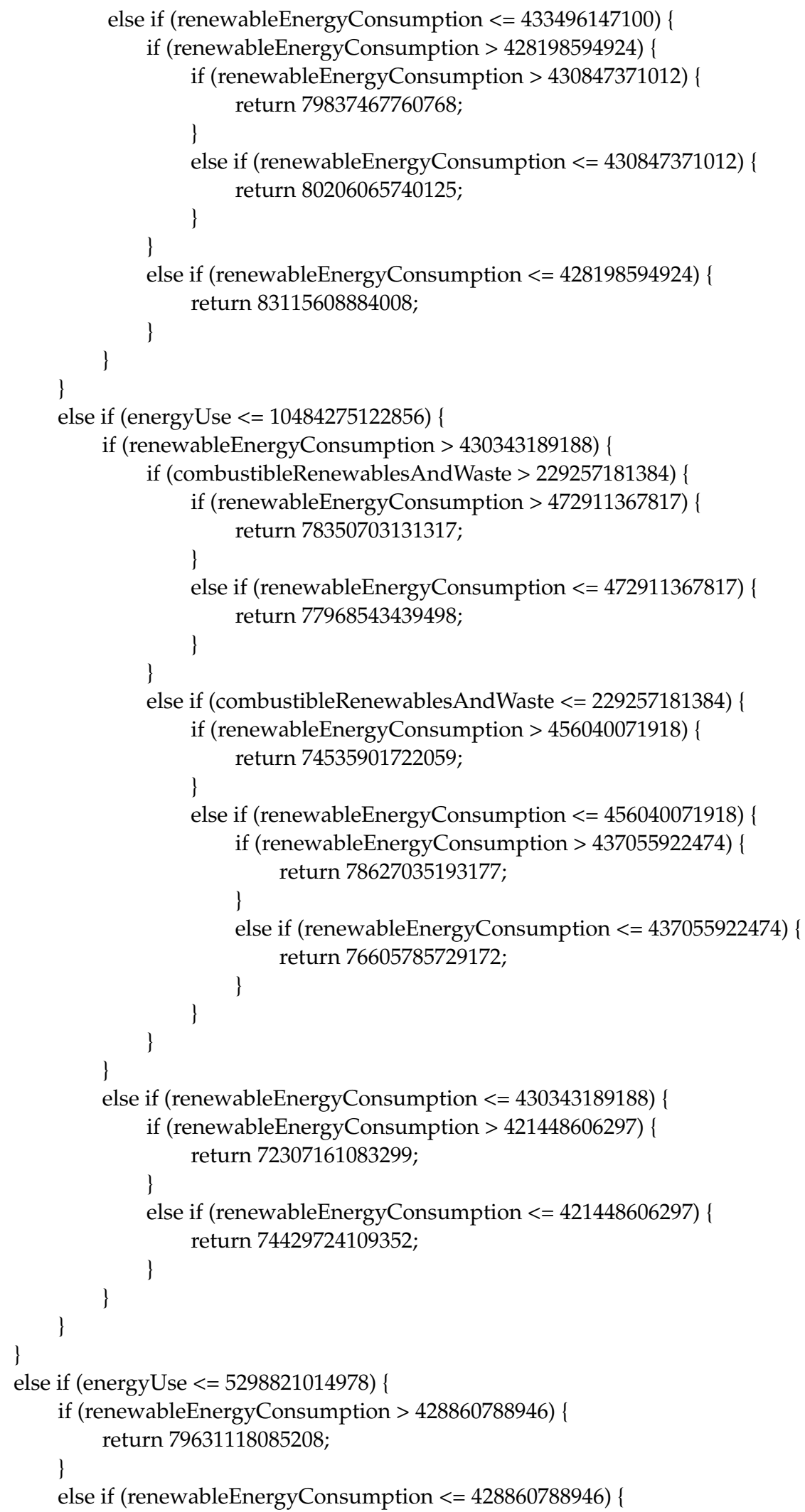


ML Algorithm: Clear commands

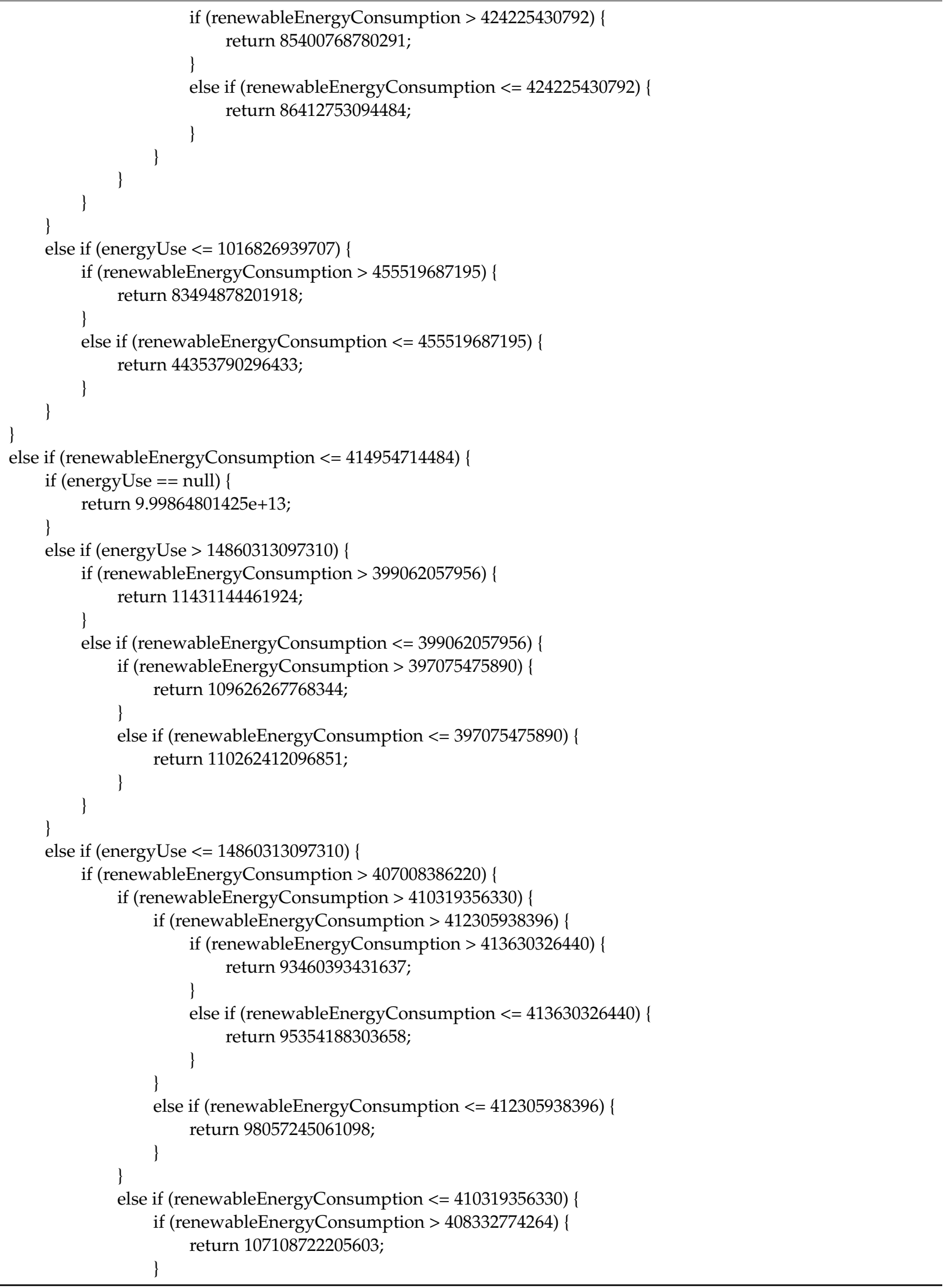




\section{Algorithm: Clear commands}

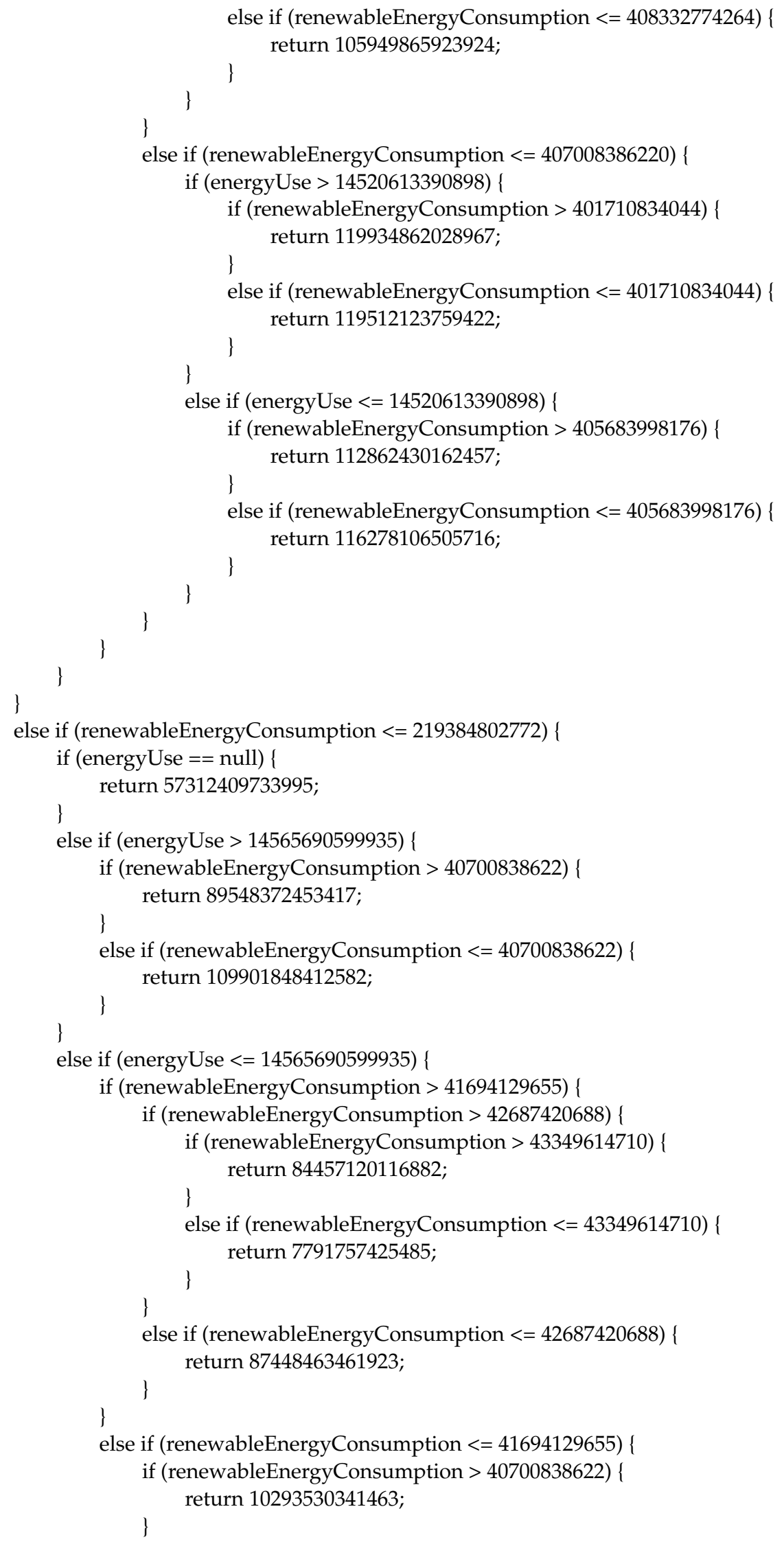




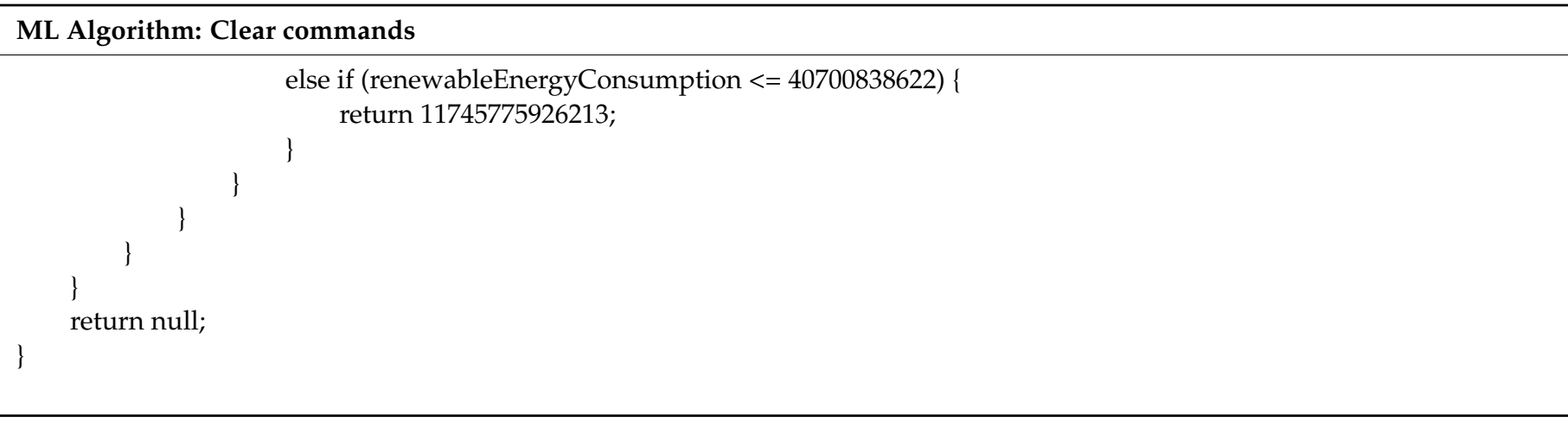

In summary, Brazil is one of the very few nations that have fully utilized renewable energy sources in the world. Different factors prompted the attention that the country has the generation and use of renewable energy. Some of these factors are the increasing Brazilian population that cannot fully be supplied with hydropower, the depletion of fossil fuel, and the increase in the number of motor vehicles and other equipment that requires energy for operation. In general, many researchers, in the face of an increase in energy consumption in Brazil, are continuing their research, in order to establish a long-term causal relationship concerning the change in economic growth in Brazil.

\section{Methods and Data}

The empirical methodology of this study uses ANNs in ML experiment with Oryx 2.8.0. software (Hyderabad, India). The aim of this paper is to estimate a possible acceleration of Brazil's GDP with more use of renewable energy consumption in a Covid-19 time. A combination of four variables that are pooled through the first differences, the squared elevation, and the logarithmic transform is used. The need for these transformations of the dataset is further explained. The goodness of the performance of the NN is covered by accuracy. We must select and adequately prepare input data and the structure of the network itself. In fact, unlike standard econometric models, ANNs do not require data transformation; therefore, they do not have the typical problems of stationarity of the time series. Since the operating logic of a NN is very different. We have to make the variables dimensionless and comparable. Then, we have to make sure that the weights are not influenced by the absolute value of the variables; in other words, variables with a higher total value are more influential than others with a lower one. As for the architecture of the constructed networks, we decided not to limit to a single intermediate layer, as, instead, stated by [45,46]. We followed [47] approach, according to whom the optimal number of nodes in the intermediate layer, which allows the network to obtain the best performance, is equal to the logarithm of the number of sample data used to estimate the network itself. In general, we followed a similar approach by [48-52]. However, see Figure A1 in the Appendix A, for the flowchart.

Although there are numerous approaches and algorithms for using ANNs, according to [53], we used the Multilayer Perceptron (MP) approach with ANNs forecast experiment. Starting by the perceptron, it is a network with $m$ of neurons; $d$ is the number of inputs, and the output $y_{j}$ is the target:

$$
y_{j}=y\left(\sum_{i=0}^{d} w_{j i} x_{i}\right)
$$

where $x_{i}$ are the inputs and $w_{j i}$ are the weights of each input combined with each output. With this architecture, we use the activation functions of the threshold function type. The final outputs of the network are, therefore, verifiable by the following expression:

$$
z_{k}=z\left(\sum_{j=0}^{m} w_{k j}^{\prime} y_{j}\right)
$$


where $z_{k}$ is the final output, $w^{\prime}{ }_{k j}$ are the weights for each processing unit, and $y_{j}$ is the signal sent by the hidden units. The bias, as a coefficient respectively of the input $x_{0}$ and $y_{0}$, was calculated by setting both of them equal to 1. Then, combining Equations (1) and (2), we can derive the final result:

$$
z_{k}=z\left(\sum_{j=0}^{m} w_{k j}^{\prime} y\left(\sum_{i=0}^{d} w_{j i}^{\prime} x_{i}\right)\right)
$$

Figure 2 shows the graphical representation of the previous equation.

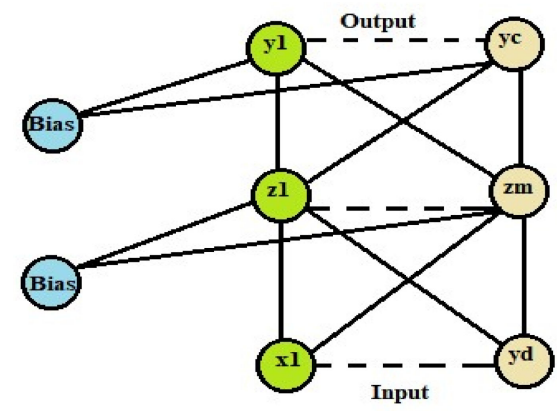

Figure 2. Multilayer Perceptron. Source: our elaboration in YeD software.

We derived data on per capita GDP in 1990 US \$ (converted at Geary-Khamis PPPs) (https:/ / conference-board.org/data/economydatabase/total-economy-databaseproductivity), per capita energy consumption ( $\mathrm{kg}$ of oil equivalent), renewable-energy consumption (\% of total final energy consumption) (https:/ / www.iea.org/data-and-statistics), and combustible renewables and waste (\% of total energy) (https://data.worldbank.org/). Using yearly data from 1990 to 2018, we obtained a total of 420 data.

\section{Results}

In this section, we analyze the results obtained through our ANNs experiment. In total, it considered thirteen inputs (with two omitted inputs) and one target. The variables were expanded through mathematical transformations (logarithms, $\ln$, and variations of the first differences, $d d$ ). Figure 3 illustrates the use of the variables of our algorithm.

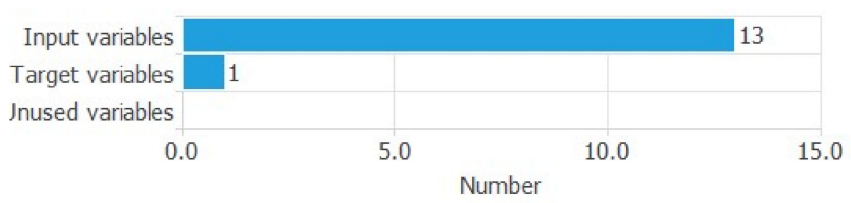

Figure 3. Variables bar chart. Source: our elaboration in Oryx 2.8.0.

The calculator has chosen 13 several inputs, compared to a single target. There are no omitted variables. Out of a total of 15 combined variables, one variable (which does not appear) represents the substrate. Through the pie chart in Figure 4, we can observe, in detail, the use of all instances in the dataset.

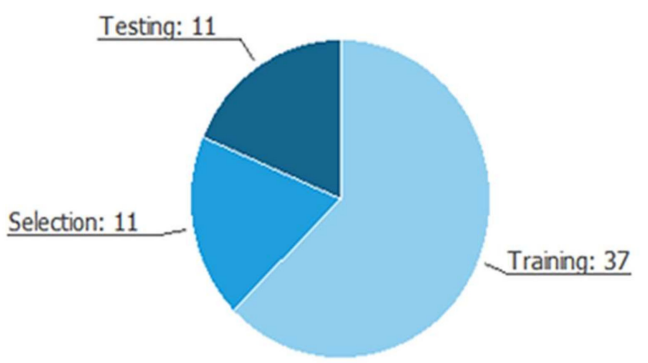

Figure 4. Instances pie chart. Source: our elaboration in Oryx 2.8.0. 
The total number of instances is 59 . The number of training instances is 37 , the number of selection instances is 11, the number of testing instances is 11, and the number of unused instances is $0(0 \%)$. Finally, after observing the behavior of the dataset concerning the processing in ML of our algorithm, we can analyze the result of the ANNs in Figure 5.

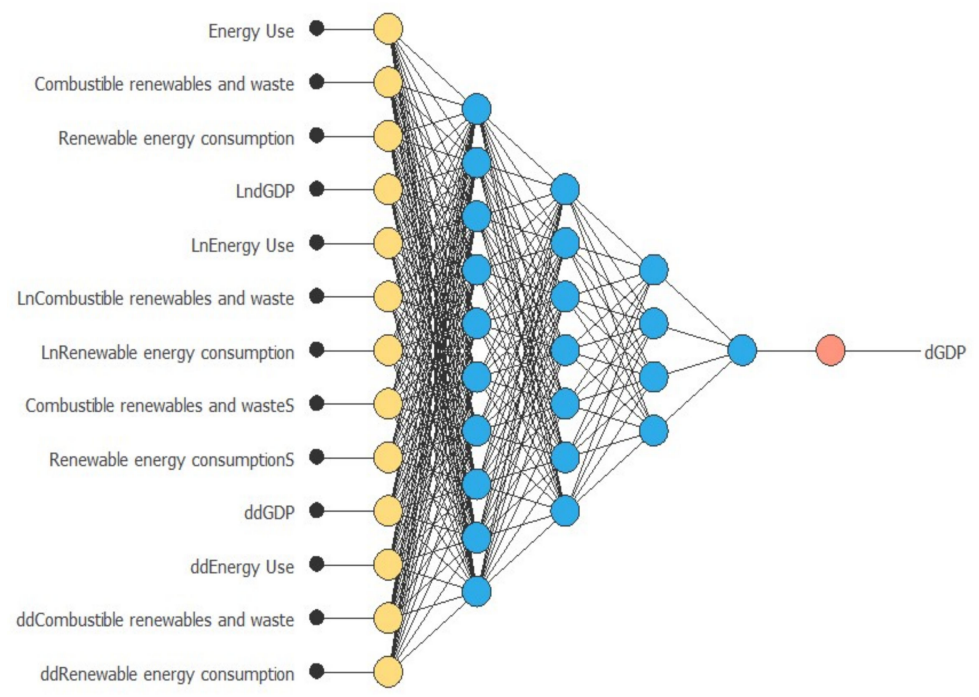

Figure 5. Artificial Neural Networks (ANNs) graph. Source: our elaboration in Oryx 2.8.0.

The ANNs graph contains a scaling layer, an NN, and an unscaling layer. The yellow circles represent the scaling neurons, the blue circles are the perceptron neurons, and the red circle the unscaling neurons. The number of inputs is equal to 13 , and the number of outputs to 1 . The degree of complexity-represented by the numbers of hidden neurons-is 10:7:4. As we can see from the result of the NN, the preset target is $d G D P$. It represents the best choice, compared to 7371 (Result $=D R_{n, k}$. In this case, $k$, a positive integer, can also be greater than or equal to $n$ ) possible combinations of between inputs, to generate a target necessary for the analysis. The Confusion Matrix in Table 1 confirms the results obtained through ANNs.

Table 1. Confusion Matrix.

\begin{tabular}{ccc}
\hline & Predicted Positive & Predicted Negative \\
\hline Actual Positive & 7043 & 257 \\
Actual Negative & 396 & 6745 \\
\hline
\end{tabular}

The results confirm the goodness of the previous outcomes shown in Figure 4 . The expected values, compared to the actual positive values, cause a change in the target 96.47 times every 100 combinations between the inputs made. Therefore, compared to the positive current values, there is only a $3.53 \%$ probability of being able to choose a different target than the one obtained in the ANNs analysis (dGDP).

We obtain the same result by observing, in the Confusion Matrix, the results between the predicted positive and negative values with the actual negative values. In this case, the probability of obtaining a different target drops to a level of $0.17 \%$. As regards the analysis of the goodness of learning and data generation concerning the obtained target, we performed the Predictive Linear Regression test (Figure 6).

The best straight line has a smaller distance, on the ordinate axis, from all the points of the diagram to the predicted and real values. Therefore, the predicted and real variables of the study (concerning the target) have a linear relationship between them. Thus, the points of the scatter plot tend to arrange themselves in a straight line. 


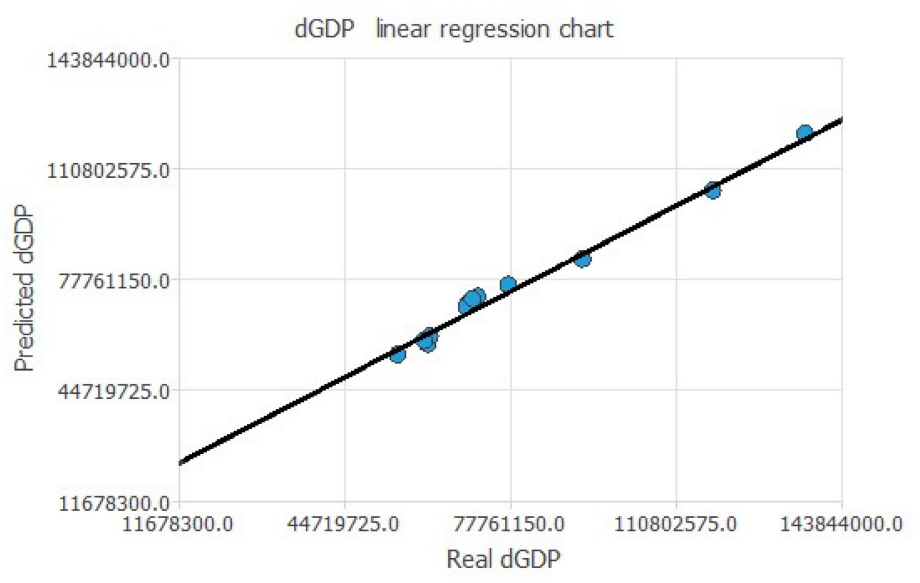

Figure 6. Predictive Linear Regression test. Source: our elaboration in Oryx 2.8.0.

The tests that we have carried out on the ANNs results confirm the generated target. The combination of inputs showed that the $d G D P$ undergoes a change after several passages. It can be considered as the output of the whole process. Despite this, we wonder which of the outputs generated a more significant variance of per capita GDP. In this way, we would have useful policy information to advise the use of adequate economic actions to accelerate Brazil's GDP. To this end, we have generated in our algorithm the ability to predict, concerning the total historical data, the variation of the target $(d G D P)$ in four iterations (ITEs). Through this procedure, we can analyze the effects of inputs on ANNs over time. Since we use annual data, the four ITEs could be interpreted as the next four years. In other words, we try to determine if one or more inputs can determine the variation of the target $d G D P$ until 2022. This process is performed through the Levenberg-Marquardt algorithm errors history (Figure 7) and the Importance test (Figure 8).

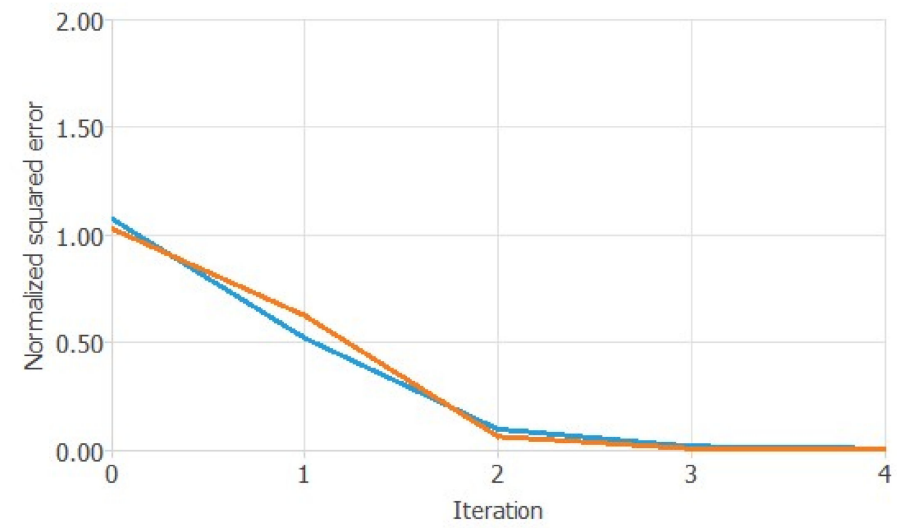

Figure 7. Levenberg-Marquardt algorithm errors history. Source: our elaboration in Oryx 2.8.0.

ITE $1 / 5$ [==============================]-30 s 2 s/step-loss: 0.0163-accuracy: 0.8858—val_loss: 0.0000e + 00—val_accuracy: 0.0000e + 00 .

ITE $2 / 5$ [==============================]-38 s 2 s/step-loss: 0.0260 -accuracy: 0.9212-val_loss: $0.0000 \mathrm{e}+00$-val_accuracy: $0.0000 \mathrm{e}+00$.

ITE $3 / 5$ [==============================]-38 s 2 s/step-loss: 0.0102—accuracy: 0.9279-val_loss: 0.0000e + 00—val_accuracy: 0.0000e + 00 .

ITE $4 / 5$ [==============================]—38 s 2 s/step—loss: 0.007—accuracy: 0.9323—val_loss: 0.0000e + 00—val_accuracy: $0.0000 \mathrm{e}+00$. 


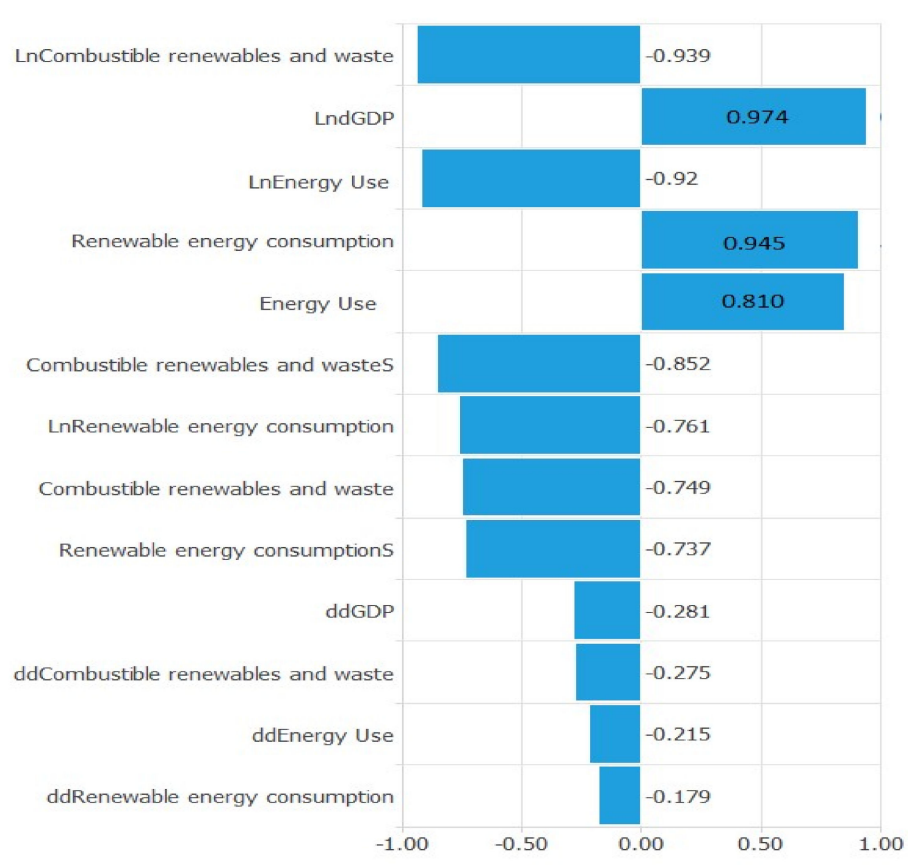

Figure 8. Importance test. Source: our elaboration in Oryx 2.8.0 and Big ML.

The results of the test are very interesting. Our algorithm, which foresees different variations over time (four years), shows that the errors squared by the predictions of the ITE decrease to be minimal to the fourth ITE. This result allows us to analyze the Importance test, since the forecast error would be minimum. Therefore, in Figure 8, we show the result of the algorithm on the importance of each input variable in generating the target $d G D P$. Each positive value represents the predictive ability, compared to our four ITEs, of causing an acceleration of the target. Negative values, on the other hand, generate the contraction effects on the $d G D P$.

The results obtained from the Importance test represent the positive and negative projections about our inputs used concerning the target $d G D P$. We can come up with interesting observations. Compared to the 13 inputs in total, three of them show a positive variation, while 10 a negative variation. More specifically, two of the three variables with a positive value are not the transforms we have created for the ANNs model. These two variables, therefore, represent the linear inputs to our target, which is also linear $(d G D P)$. Thus, we can eliminate the $\operatorname{LndGDP}$ variable from consideration also because, being itself a GDP logarhythmic evaluation, it would suffer from collinearity with target. Thus, the inputs that generate a positive change in the $d G D P$ are renewable energy consumption, with a value of 0.945 , and energy, use with a value of 0.810 .

This result highlights that the renewable energies could represent the variables capable of accelerating Brazil's economic growth. Energy use (more generally) also has a positive effect on GDP growth. However, it is lower than the renewable energies' one. An explanation of this result could be the following. The projections concerning four ITEs could be based on the assumption that there will be no friction on the labor market following the transition of the Brazilian economy. In particular, the workforce will adapt to structural changes as regards to skills requirements. This situation presupposes that funding is made available for the restructuring, and the country energy system moves towards renewable energy. In this scenario, we could have a positive effect not only on the climate, but also in terms of GDP growth and new employment. As a result of the investment activity necessary to achieve this transition, together with the impact of the reduction in spending on the import of fossil fuels.

The shift towards the production of capital goods, such as renewable energy equipment and machinery, will lead to a significant increase in the demand for labor from the 
activities connected to it. We must also say that, if this acceleration of the energy transition will increase GDP and jobs opportunities globally, the gains are not automatic. In fact, some communities could suffer negative impacts, especially in areas of the country that have so far relied heavily on fossil fuels. It is, therefore, necessary to invest also in training and retraining of workers and in social security measures for those who cannot be relocated. Thus, we can say that, by accelerating the spread of renewable sources, it is possible-at the same time- to fuel economic growth, create new job opportunities, improve human well-being, and contribute to safeguarding the future climate. The increase in distribution will be able to meet the energy needs of a growing population, guide development, and improve well-being, whilst reducing greenhouse gas emissions and increasing the productivity of natural resources.

Furthermore, our results provide empirical evidence that economic growth and environmental conservation are fully compatible and that the conventional consideration of the trade-off between the two is obsolete and erroneous. In addition, the acceleration effect of the input of renewable energies is the best choice for policymakers in a period of economic uncertainty such as the present time, due to Covid-19.

\section{Conclusions and Policy Implications}

Renewable energy is one of the critical drivers of the Brazilian economy after the government shifted its effort in full utilization of clean energy. Numerous researchers are persuaded of the presence of a positive correlation between economic development and renewable energy consumption worldwide. Brazil is one of the largest consumers and producers of energy, and it is experiencing a substantial economic growth. However, this growth could withdraw itself, giving rise, instead, to a real economic crisis caused by the Covid-19 pandemic. Therefore, economic policy solutions are needed. In particular, they should be based on investments in renewable energy capable of accelerating a long-term development process. Over the recent past, there has been growing propulsion in Brazil towards production renewable energy in the national energy sector. Renewable energy is currently touted as the future fuel, and Brazil is not left behind in the maximum utilization of the energy in its economic production. Empirical findings show that an ever-greater use of renewable energies may sustain the economic growth process.

In fact, through a model of ANNs, we have noticed how an increasing consumption of renewable energies trigger an acceleration of the GDP, compared to other energy variables considered in the model. Compared to standard econometric models, this experiment was able to show and select which input can generate the best target. The best output was per capita GDP. A positive variation of it, through a four ITEs predictive process, was due to an acceleration of renewable energies. Therefore, we can conclude that, during the international pandemic caused by the Covid-19 virus, Brazil might anticipate the adverse effects that will spill on the economic system. Using defective policies, intensifying its energy structural change process by promoting a more intensive use of renewable energy.

Author Contributions: Conceptualization, C.M.; methodology, C.M. and M.M.; software, C.M.; validation, C.M.; formal analysis, C.M. and M.M.; investigation, M.M. and G.M.; resources, M.M.; data curation, M.M.; writing-original draft preparation, C.M., M.M. and G.M.; writing-review and editing, G.M.; visualization, G.M.; supervision, G.M.; project administration, C.M., M.M. and G.M. All authors have read and agreed to the published version of the manuscript.

Funding: This research received no external funding.

Data Availability Statement: The data presented in this study are available on request from the corresponding author.

Conflicts of Interest: The authors declare no conflict of interest. 


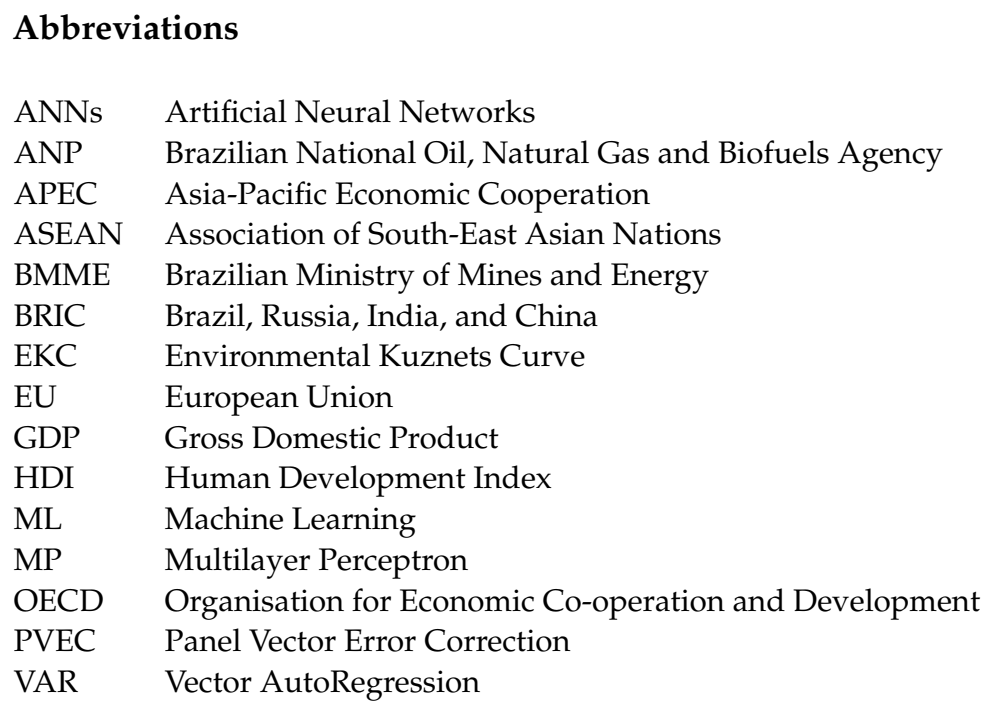

\section{Appendix A}

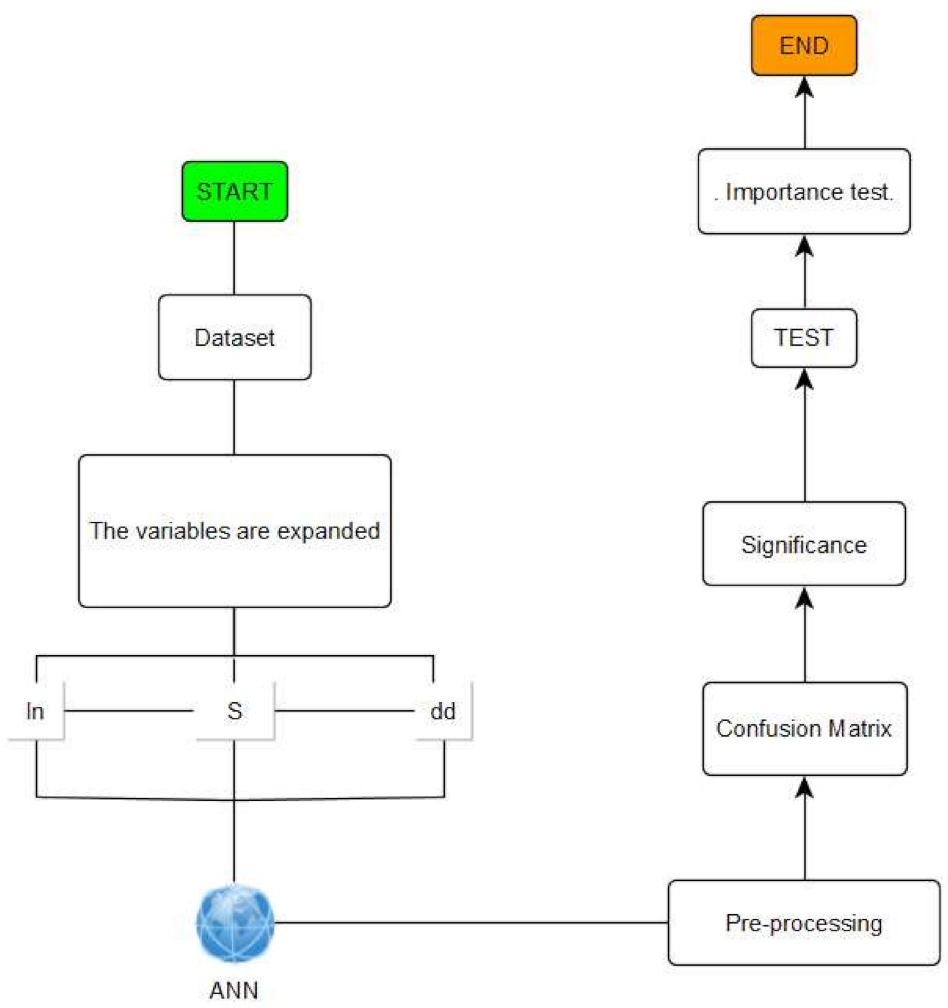

Figure A1. ANNs flowchart. Our elaborations in YeD software.

\section{References}

1. Magazzino, C. Energy Consumption and GDP in Italy. Environ. Dev. Sustain. 2014, 16, 137-153.

2. Ozturk, I. A literature survey on energy-growth nexus. Energy Policy 2010, 38, 340-349. [CrossRef]

3. Magazzino, C. Electricity Demand, GDP and Employment: Evidence from Italy. Front. Energy 2014, 8, 31-40. [CrossRef]

4. Payne, J.E. A survey of the electricity consumption-growth literature. Appl. Energy 2010, 87, 723-731. [CrossRef]

5. Kraft, J.; Kraft, A. On the Relationship between Energy and GNP. J. Energy Dev. 1978, 3, 401-403.

6. Tiba, S.; Omri, A. Literature survey on the relationships between energy, environment and economic growth. Renew. Sustain. Energy Rev. 2017, 69, 1129-1146. [CrossRef]

7. Magazzino, C. The relationship among real GDP, $\mathrm{CO}_{2}$ emissions, and energy use in South Caucasus and Turkey. Int. J. Energy Econ. Policy 2016, 6, 672-683. 
8. Dogan, E. Analyzing the linkage between renewable and non-renewable energy consumption and economic growth by considering structural break in time-series data. Renew. Energy 2016, 99, 1126-1136. [CrossRef]

9. Brady, G.L.; Magazzino, C. The relationship among renewable energy, economic growth, labor and capital formation in Italy. Riv. Studi Sulla Sostenibilità 2018, 1, 35-48.

10. Magazzino, C. Renewable energy consumption-economic growth nexus in Italy. Int. J. Energy Econ. Policy 2017, 7, 119-127.

11. Aslan, A.; Ocal, O. The role of renewable energy consumption in economic growth: Evidence from asymmetric causality. Renew. Sustain. Energy Rev. 2016, 60, 953-959.

12. Aslan, A. The causal relationship between biomass energy use and economic growth in the United States. Renew. Sustain. Energy Rev. 2016, 57, 362-366. [CrossRef]

13. Inglesi-Lotz, R. The impact of renewable energy consumption to economic growth: A panel data application. Energy Econ. 2016, 53, 58-63. [CrossRef]

14. Rafindadi, A.A.; Ozturk, I. Effects of financial development, economic growth and trade on electricity consumption: Evidence from post-Fukushima Japan. Renew. Sustain. Energy Rev. 2016, 54, 1073-1084. [CrossRef]

15. Bhattacharya, M.; Paramati, S.R.; Ozturk, I.; Bhattacharya, S. The effect of renewable energy consumption on economic growth: Evidence from the top 38 countries. Appl. Energy 2016, 162, 733-741. [CrossRef]

16. Magazzino, C. A Panel VAR Approach of the Relationship among Economic Growth, $\mathrm{CO}_{2}$ Emissions, and Energy Use in the ASEAN-6 Countries. Int. J. Energy Econ. Policy 2014, 4, 546-553.

17. Magazzino, C.; Schneider, N. The Causal Relationship between Primary Energy Consumption and Economic Growth in Israel: A Multivariate Approach. Int. Rev. Environ. Resour. Econ. 2020, 14, 417-491. [CrossRef]

18. Furuoka, F. Renewable electricity consumption and economic development: New findings from the Baltic countries. Renew. Sustain. Energy Rev. 2017, 71, 450-463. [CrossRef]

19. Destek, M.A.; Aslan, A. Renewable and non-renewable energy consumption and economic growth in emerging economies: Evidence from bootstrap panel causality. Renew. Energy 2017, 111, 757-763. [CrossRef]

20. Magazzino, C. Economic growth, $\mathrm{CO}_{2}$ emissions, and energy use in Israel. Int. J. Sustain. Dev. World Ecol. 2015, $22,89-97$.

21. Menyah, K.; Wolde-Rufael, Y. $\mathrm{CO}_{2}$ emissions, nuclear energy, renewable energy, and economic growth in the U.S. Energy Policy 2010, 38, 2911-2915. [CrossRef]

22. Ocal, O.; Aslan, A. Renewable energy consumption-economic growth nexus in Turkey. Renew. Sustain. Energy Rev. 2013, 28, 494-499. [CrossRef]

23. Lise, W.; Van Montfort, K. Energy consumption and GDP in Turkey: Is there a co-integration relationship? Energy Econ. 2007, 29, 1166-1178. [CrossRef]

24. Sadorsky, P. Renewable energy consumption and income in emerging economies. Energy Policy 2009, 37, 4021-4028. [CrossRef]

25. Kahia, M.; Aïssa, M.S.B.; Lanouar, C. Renewable and non-renewable energy use-economic growth nexus: The case of MENA net oil importing countries. Renew. Sustain. Energy Rev. 2017, 71, 127-140. [CrossRef]

26. Amri, F. The relationship amongst energy consumption (renewable and non-renewable), and GDP in Algeria. Renew. Sustain. Energy Rev. 2017, 76, 62-71. [CrossRef]

27. Shahbaz, M.; Mallick, H.; Mahalick, M.K.; Sadorsky, P. The role of globalization on the recent evolution of energy demand in India: Implications for sustainable development. Energy Econ. 2016, 55, 52-68. [CrossRef]

28. Saidi, K.; Mbarek, M.B. Nuclear energy, renewable energy, $\mathrm{CO}_{2}$ emissions, and economic growth for nine developed countries: Evidence from panel Granger causality tests. Prog. Nucl. Energy 2016, 88, 364-374. [CrossRef]

29. Magazzino, C. On the Relationship between Disaggregated Energy Production and GDP in Italy. Energy Environ. 2012, 23, 1191-1207. [CrossRef]

30. Apergis, N.; Payne, J.E. Renewable energy consumption-growth nexus in Central America. Appl. Energy 2011, 88, 343-347. [CrossRef]

31. Magazzino, $\mathrm{C}$. The relationship among economic growth, $\mathrm{CO}_{2}$ emissions, and energy use in the APEC countries: A panel VAR approach. Environ. Syst. Decis. 2017, 37, 353-366. [CrossRef]

32. Magazzino, C. Economic Growth, $\mathrm{CO}_{2}$ Emissions and Energy Use in the South Caucasus and Turkey: A PVAR analyses. Int. Energy J. 2016, 16, 153-162.

33. Huang, B.N.; Hwang, M.J.; Yang, C.W. Causal relationship between energy consumption and GDP growth revisited: A dynamic panel data approach. Ecol. Econ. 2008, 67, 41-54. [CrossRef]

34. Ciarreta, A.; Zarraga, A. Economic growth-electricity consumption causality in 12 European countries: A dynamic panel data approach. Energy Policy 2010, 38, 3790-3796. [CrossRef]

35. Lee, C.C.; Chang, C.P. Energy consumption and economic growth in Asian economies: A more comprehensive analysis using panel data. Resour. Energy Econ. 2008, 30, 50-65.

36. Magazzino, C.; Mele, M.; Schneider, N. A Machine Learning approach on the relationship among solar and wind energy production, coal consumption, GDP, and $\mathrm{CO}_{2}$ emissions. Renew. Energy 2020, 167, 99-115. [CrossRef]

37. Sugiawan, Y.; Managi, S. New evidence of energy-growth nexus from inclusive wealth. Renew. Sustain. Energy Rev. 2019, 103, 40-48. [CrossRef]

38. Wang, X.; Luo, D.; Zhao, X.; Sun, Z. Estimates of energy consumption in China using a self-adaptive multi-verse optimizer-based support vector machine with rolling cross-validation. Energy 2018, 152, 539-548. [CrossRef] 
39. Zaidi, S.M.A.; Chandola, V.; Allen, M.R.; Sanyal, J.; Stewart, R.N.; Bhaduri, B.L.; McManamay, R.A. Machine learning for energy-water nexus: Challenges and opportunities. Big Earth Data 2018, 2, 228-267. [CrossRef]

40. Mele, M.; Magazzino, C. Pollution, economic growth, and COVID-19 deaths in India: A machine learning evidence. Environ Sci Pollut Res. 2020, 28, 2669-2677. [CrossRef]

41. Magazzino, C.; Mele, M.; Schneider, N. The relationship between air pollution and COVID-19-related deaths: An application to three French cities. Appl. Energy 2020, 279, 115835. [CrossRef] [PubMed]

42. Oliveira, J.F.G.; Trindade, T.C.G. Sustainability Performance Evaluation of Renewable Energy Sources: The Case of Brazil; Springer: Berlin/Heidelberg, Germany, 2018.

43. Newman, P. The rise and rise of renewable cities. Renew. Energy Environ. Sustain. 2017, 2, 1-5. [CrossRef]

44. Vaona, A. Granger non-causality tests between (none) renewable energy consumption and output in Italy since 1861: The (ir) relevance of structural breaks. Energy Policy 2012, 45, 226-236. [CrossRef]

45. Gareta, R.; Romeo, L.M.; Gil, A. Forecasting of electricity prices with neural networks. Energy Convers. Manag. 2006, 47, 1770-1778. [CrossRef]

46. Singhal, D.; Swarup, K.S. Electricity price forecasting using artificial neural networks. Int. J. Electr. Power Energy Syst. 2011, 33, 550-555. [CrossRef]

47. Wanas, N.; El-Saban, M.; Ashour, H.; Ammar, W. Automatic Scoring of Online Discussion Posts. In Proceedings of the Workshop on Information Credibility on the Web; Association for Computing Machinery: New York, NY, USA, 2008; pp. 19-26.

48. Magazzino, C.; Mele, M.; Schneider, N. A D2C Algorithm on the Natural Gas Consumption and Economic Growth: Challenges faced by Germany and Japan. Energy 2021, 219, 119586. [CrossRef]

49. Magazzino, C.; Mele, M.; Schneider, N.; Sarkodie, S.A. Waste generation, Wealth and GHG emissions from the waste sector: Is Denmark on the path towards Circular Economy? Sci. Total Environ. 2021, 755, 142510. [CrossRef]

50. Magazzino, C.; Mele, M.; Schneider, N. The relationship between municipal solid waste and greenhouse gas emissions: Evidence from Switzerland. Waste Manag. 2020, 113, 508-520. [CrossRef]

51. Magazzino, C.; Mele, M.; Schneider, N.; Vallet, G. The Relationship between Nuclear Energy Consumption and Economic Growth: Evidence from Switzerland. Environ. Res. Lett. 2020, 15, 0940a5. [CrossRef]

52. Mele, M.; Magazzino, C.; Schneider, N.; Strezov, V. $\mathrm{NO}_{2}$ levels as a contributing factor to COVID-19 deaths: The first empirical estimate of threshold values. Environ. Res. 2021, 194, 110663. [CrossRef]

53. White, H. Economic Prediction Using Neural Networks: The Case of IBM Daily Stock Returns. In Proceedings of the IEEE 1988 International Conference on Neural Networks, San Diego, CA, USA, 24-27 July 1988; Volume 2, pp. 451-458. 